\title{
INDICADORES DE DESEMPENHO NA INDÚSTRIA NAVAL BRASILEIRA: UM ESTUDO DE CASO
}

\section{PERFORMANCE INDICATORS IN BRAZILIAN NAVAL INDUSTRY: A CASE STUDY}

\author{
Flávia Czarneski ${ }^{1}$; Floriano Carlos Martins Pires Júnior ${ }^{2}$ \\ ${ }^{1}$ Universidade Federal de Rio Grande - FURG \\ flavia.furg@gmail.com \\ ${ }^{2}$ Universidade Federal do Rio de Janeiro - UFRJ \\ floriano@peno.coppe.ufrj.br
}

\begin{abstract}
Resumo
Na última década houve uma retomada de investimentos na construção naval brasileira o que resultou em uma expansão e modernização da capacidade produtiva dos estaleiros nacionais. Os estaleiros nacionais ainda precisam atingir um nível de excelência operacional compatível com o observado nos países líderes de mercado $O$ trabalho apresenta tópicos adotados por estaleiros estrangeiros bem sucedidos e que podem ser implantadas pelos estaleiros brasileiros com o intuito de torná-los competitivos mundialmente. Para isso, realizou-se um estudo de caso em um estaleiro nacional, cujo foco foi o levantamento das tecnologias e processos em uso nesse estaleiro e a classificação com relação às melhores práticas mundiais (benchmarks). Um método de benchmarking desenvolvido para construção de navios foi utilizado no presente estudo. $O$ trabalho pode servir como fonte de informações para realizar ajustes para melhorias em processos produtivos, redução de tempos de ciclo e melhor utilização da mão-de-obra. Dessa forma, pode contribuir para posicionar a situação atual do estaleiro e verificar as necessidades para torná-lo competitivo internacionalmente.
\end{abstract}

Palavras-chave: indústria naval; indicadores de desempenho; capacidade produtiva.

\section{Introdução}

Na década de setenta, o Japão se destacava em primeiro lugar e a Coreia do Sul iniciou seus trabalhos nessa área, e hoje é uma grande potência da construção naval no mundo.

Nas décadas seguintes, o Brasil passou por um período de estagnação do setor. Mas na última década houve uma retomada de investimentos na construção naval brasileira o que resultou em uma expansão e modernização da capacidade produtiva dos estaleiros nacionais. Para Dores et al (2012) tal fato decorreu, principalmente, do crescimento das atividades petrolíferas offshore, que acarretou a necessidade de novas embarcações para esse mercado, e de uma política voltada ao desenvolvimento da indústria nacional. 
No entanto, apesar do crescimento e modernização do setor, muitos estaleiros estrangeiros possuem um nível de excelência operacional superior aos estaleiros brasileiros. Santos (2011) menciona que a competitividade da indústria naval mundial tem levado os estaleiros a evoluírem os seus processos produtivos procurando reduzir custos e o tempo de construção. Esta não é uma tarefa simples, pois, em princípio, os pedidos são personalizados para se atender às necessidades de um cliente específico, exigindo assim, um planejamento apurado no projeto e no processo de construção. As empresas deste setor precisam desenvolver uma série de atividades em um ambiente econômico-industrial complexo, sofisticado e altamente competitivo. Os projetos de engenharia naval são complexos e envolvem inúmeras atividades multidisciplinares, desempenhadas em um longo período de tempo, que mobilizam quantitativos vultosos de recursos de diversas naturezas.

Para Souza (2009) a indústria de construção naval tem particularidades que definem a forma como ela é organizada. Tais particularidades têm impactos importantes nos processos de um estaleiro, como: na organização dos fluxos de produção; na estrutura organizacional; no nível de desenvolvimento tecnológico; nas atividades de pesquisa, desenvolvimento e inovação; e na produtividade de processos.

Com a análise destes fatores pode-se determinar quais são os melhores conceitos, técnicas e ferramentas a serem aplicados com o objetivo de aumentar os níveis de eficiência e de produtividade dos estaleiros.

A presente pesquisa busca analisar as práticas gerenciais adotadas por estaleiros estrangeiros bem sucedidos e que podem ser implantadas pelos estaleiros brasileiros com o intuito de torná-los competitivos mundialmente. Para isso, realizou-se um case em um estaleiro nacional onde o principal foco foi levantar as tecnologias e processos em uso neste estaleiro e classificá-las em relação às melhores práticas mundiais (benchmarking). Este trabalho servirá de base para futuras pesquisas neste estaleiro. Será um levantamento para avaliação de diferentes cenários, identificação de gargalos produtivos e geração de alternativas para melhorias da situação atual. Foram analisados os níveis de produção, de utilização de mão-de-obra, os processos e a estrutura de ocupação do estaleiro. Este trabalho servirá como fonte de informações para realizar ajustes para melhorias em processos produtivos, redução de tempos de ciclo e melhor utilização da mão-de-obra. Com isso, poder-se-á posicionar a situação atual do estaleiro e verificar as necessidades para torná-lo competitivo internacionalmente.

Para realizar este trabalho, inicialmente foi elaborado um WBS (Work Breakdown Structure) para mapear as atividades do estaleiro. Após foi analisada sua capacidade produtiva e sua utilização de mão-de-obra, de modo a produzir um mapa com a situação atual do estaleiro.

Serão analisados os potenciais de produtividade da mão-de-obra bem como o de tempo de produção em um estaleiro nacional. Com estes dados, serão formulados novos cenários 
representativos da indústria naval brasileira, para que seja possível analisar índices de produtividade alcançáveis referentes aos fatores estudados.

\section{Metodologia}

$\mathrm{Na}$ presente pesquisa foram estabelecidos os conceitos para o desenvolvimento deste trabalho, através de uma revisão bibliográfica. Posteriormente, a partir do estabelecimento das bases conceituais e com o uso da técnica de análise de conteúdo, foram determinadas dimensões de análise relacionadas a indústria naval offshore. Para Campos (2004) o método de análise de conteúdo constitui-se em um conjunto de técnicas utilizadas na análise de dados qualitativos. Com as dimensões de análise determinadas para a indústria naval offshore foram elaboradas as métricas de desempenho (Benchmarking).

Foi elaborado uma estrutura analítica de projeto (WBS) que possibilitou uma visão do gerenciamento de um estaleiro offshore compatível com os sistemas de produção tipicamente empregados pelos estaleiros brasileiros.

Foram analisados fatores como: a capacidade física, a tecnologia utilizada, característica do ambiente industrial, a produtividade, o tempo de produção e a qualidade.

Trabalhos anteriores, a partir da análise de WBS, definiram benchmarking internacionais associados à construção de navios, (PIRES et al, 2007). Neles foram analisadas práticas gerenciais e tecnologias adotadas por estaleiros estrangeiros bem sucedidos e que poderiam ser implantadas pelos estaleiros brasileiros com o intuito de torná-los competitivos mundialmente. O trabalho de Pires et al (2007) foi utilizado como referência, fazendo sua transposição para a indústria offshore.

Esta etapa da pesquisa teve como meta a ser atingida, e passível de acompanhamento, a confecção de Relatório Técnico contendo a aplicação de WBS e a elaboração de índices de desempenho.

Foi adotado o estudo de caso como estratégia de investigação, com o intuito de determinar como um estaleiro nacional se posiciona no mercado em comparação a estaleiros internacionais. Foram realizadas entrevistas estruturadas com os Diretores e Gerentes (Gestores) do Estaleiro para que se pudesse diagnosticar a situação atual do estaleiro. O estudo de caso consiste, segundo Prodanov (2013), em coletar e analisar informações sobre determinado indivíduo, uma família, um grupo ou uma comunidade, a fim de estudar aspectos variados de sua vida, de acordo com o assunto da pesquisa. Para o autor, trata-se de um tipo de pesquisa qualitativa e/ou quantitativa, entendido como uma categoria de investigação que tem como objeto o estudo de uma unidade de forma aprofundada, podendo tratar- se de um sujeito, de um grupo de pessoas, de uma comunidade etc. 


\section{A Indústria Naval}

A indústria de construção naval tem como principal missão suprir o mercado com novos navios. No entanto, a fabricação de um navio é um projeto de engenharia muito complexo, com inúmeras atividades multidisciplinares. Essas atividades são desempenhadas em um longo período de tempo e com um vultuoso quantitativo de recursos.

Devido a competitividade na indústria naval, os estaleiros precisaram evoluir seus processos produtivos visando a redução dos custos e do tempo de fabricação. Esta não é uma tarefa simples, pois em geral os pedidos são personalizados para se atender às necessidades de um cliente especifico, exigindo um planejamento específico do projeto e no processo de construção.

\subsection{Indústria Naval Mundial}

A indústria naval caracteriza-se pela fabricação de um bem de capital de alto valor unitário, produzido sob encomenda. Suas atividades, conforme Santos (2011) podem ser divididas em três categorias: atividades não voltadas para a navegação, atividades relativas ao produto navio, e a própria construção naval. A primeira abrange uma ampla variedade de produtos, como armamentos, alguns tipos de materiais de transportes e equipamentos para exploração marítima de petróleo (offshore).

Já a segunda refere-se a componentes e peças, que em sua maioria são fabricados por um setor próprio, o de navipeças. Incluem também atividades específicas realizadas no navio, como obras de conversão e upgrading, reparos e a própria transformação da embarcação em sucata ao final de sua vida útil.

As navipeças podem ser oferecidas por empresas que se dedicam à produção de vários tipos de produtos, como peças para navios ou motores marítimos. Uma dificuldade dessas empresas é a infraestrutura de assistência técnica necessária, pois um navio pode precisar de peças de reposição em qualquer parte do mundo, exigindo presença de mão-de-obra especializada e estoques de peças nos principais portos mundiais. Assim, existe uma estrutura de mercado oligopolizada que influencia até mesmo no mercado secundário de navios, pois a procedência das peças de uma embarcação é relevante na hora da revenda.

A terceira representa a construção naval. Segundo Santos (2011) a construção naval civil é abordada sob duas subdivisões: os transportes marítimos e a área offshore. Os transportes marítimos se subdividem conforme a carga, que pode ser de granéis (líquidos e sólidos) e carga geral. Os granéis representam o segmento que apresenta grande competição entre os transportadores, ao contrário da carga geral. Já a carga geral constitui o principal mercado mundial de marinha mercante, dominado pelo transporte de contêineres. É também o segmento que apresenta as maiores mudanças operacionais como o fim das conferências fechadas, diminuição da regulamentação, 
navios especializados e de alto valor, portos e terminais dedicados e operações intermodais sofisticadas.

Na história da indústria naval, segundo Santos (2011), o comércio cresceu a taxas elevadas e a frota da marinha mercante mundial acompanhou este crescimento após a II Guerra Mundial. Nessa época, os Estados Unidos dominavam a indústria naval mundial com uma enorme produção para a marinha de guerra, substituindo o Reino Unido. Depois disso, o Japão, entre o período da metade da década de 50 e a década de 70, assumiu a liderança do setor.

Com a crise mundial de 1973, a demanda por navios diminuiu. Nessa época o Brasil e a Coreia entraram nesse mercado e enfrentaram fabricantes tradicionais que lutavam para assegurar duas posições.

A partir da segunda metade da década de 70, muitos estaleiros faliram. O governo exerceu forte influência neste processo. Nos países europeus, as estratégias defensivas incluíam até mesmo estatização para evitar falências. Já no Japão e na Coreia, foram adotadas estratégias agressivas baseadas na presença de grandes incentivos governamentais.

O segundo choque do petróleo, em 1979, reduziu novamente as encomendas do setor, resultando em uma nova queda de produção por volta de 1983. Foi necessária uma reestruturação da indústria naval, com incentivos do governo. No entanto, nos últimos anos a indústria naval tem evoluído. O crescimento médio anual para os períodos entre 1997-2001 e 2002- 2006 foi de 2,3\% e $10,9 \%$ respectivamente (SANTOS, 2011).

Atualmente, o mercado é dominado por três produtores asiáticos: China, Coreia do Sul e Japão, com a produção europeia mais concentrada em nichos e equipamentos sofisticados, e os Estados Unidos mais dedicados à produção militar (KUBOTA, 2013).

Em 2010, a China se tornou o maior construtor naval do mundo com relação a capacidade de construção e novos pedidos, de acordo com estatísticas divulgadas pelo Ministério da Indústria e Informação da China (KONRAD, 2011).

Embora a China entrou para o mundo da construção naval no mercado como uma empresa de construção naval de baixo custo na década de 1980, os estaleiros chineses têm sido apenas um concorrente muito sério nos últimos anos. A carteira de pedidos chinês ampliado de 1,9 bilhão CGT (Compensated Gross Tonnes - arqueação bruta compensada) em 1998 e 62 bilhões em CGT em 2008, um crescimento mais rápido do que a carteira de pedidos em todo o mundo (Ecorys, 2009 apud Mickeviciene, 2011). Este crescimento contou com um com forte apoio governamental e grandes investimentos, além de incluir mudanças na estrutura de seus produtos para serviços mais sofisticados, tecnologias de modernização, incorporação de estaleiros para o desenvolvimento dos gigantes especializadas. 
Para Collins e Grubb (2011) o crescimento notável de construção naval da China tem sido parcialmente alimentado por um boom global do mercado de transporte marítimo global. Os autores salientam que o foco da China em alcançar o domínio mundial de construção naval comercial depende da continuidade das condições geopolíticas no mundo atual.

As políticas setoriais implementadas por governos de vários países com o intuito de favorecer suas empresas e manter o nível de capacidade elevado, marcam a evolução da indústria naval mundial.

\subsection{Indústria Naval Brasileira}

A indústria da construção naval brasileira tem seu pioneirismo com Irineu Evangelista de Souza, mais conhecido como Barão de Mauá. Segundo Caldeiras (1995); Lima e Velasco (1998), Barão de Mauá foi um homem com grande visão empreendedora, tanto na indústria como no comércio. Em 1845 criou o Estaleiro da Companhia Ponta da Areia, construído com grande mobilização de recursos privados de terceiros - nacionais e internacionais. Nele foram construídos 72 navios, dando início à indústria naval brasileira.

Apesar do pioneirismo do Barão de Mauá na construção naval, o setor somente conseguiu se reerguer um século depois, em um cenário completamente distinto, desta vez, com o apoio e proteção do governo. De acordo com Moura (2008), o setor passou a ter uma atenção especial a partir de 1958, quando o então Presidente do Brasil Juscelino Kubitschek definiu um plano de metas.

No entanto, a construção naval sofreu um impacto negativo substancial, quando aconteceu a primeira crise do petróleo, pois houve uma onda de recessão mundial. Mesmo assim, a construção naval brasileira continuou a ter uma política governamental visando a desenvolvimento do setor, no governo do presidente em exercício da época, Ernesto Geisel, entre 1975 e 1979. Estabeleceu-se, depois, o II Plano da Construção Naval, focado na estratégia de crescimento acelerado (SANTOS, 2011).

Lima e Velasco (1998) salientam que esses planos e incentivos possibilitaram que o país alcançasse nos anos 70 a condição de segundo parque mundial de construção naval. Isso ocorreu em virtude dos dois planos da construção naval implantados no Brasil e da recessão mundial que dificultou as operações de diversos estaleiros internacionais.

O Brasil então passou a ocupar a segunda posição no cenário mundial da construção naval. Esse fator contribuiu para o desenvolvimento de empresas que abasteciam o mercado de navipeças e de bens de capital, universidades para geração de mão-de-obra especializada para o setor, escolas técnicas etc. Nesse período, o Brasil empregava cerca de 39.000 trabalhadores diretamente no segmento da construção naval, e projetava-se que geraria por volta de 5.000 empregos indiretos, 
totalizando aproximadamente 240.000 empregos provenientes dessa economia industrial (DIEESE apud MOURA, 2008).

No entanto, nos anos 90, cessou a maior parte das encomendas dos armadores aos estaleiros brasileiros, juntamente com os planos de estímulo à produção. Desta forma, sob regime de forte proteção e incentivo que havia alcançado o posto de segundo parque industrial naval mundial, em toneladas de porte bruto (TPB) construídas, e tendo chegado a empregar diretamente mais de 40 mil trabalhadores, a indústria naval brasileira não logrou atingir um grau satisfatório de competitividade internacional (PASIN, 2002).

Em 2000, a indústria naval brasileira iniciou movimento de retomada da produção, impulsionada pelas encomendas da PETROBRAS que lançou o programa de substituição da frota de navios de apoio offshore. O resultado é que a indústria chegou ao final do primeiro semestre de 2002 em face de uma nova realidade, onde o principal desafio não são mais as encomendas, e sim como reativar instalações no curto prazo e montar uma competente capacidade produtiva, para atendê-las (SANTOS, 2011).

A indústria naval brasileira passa por um processo notável de expansão. Entretanto, alguns dos problemas críticos que ainda persistem podem vir a impor barreiras à consolidação do setor. $\mathrm{O}$ nível elevado do risco-estaleiro percebido por armadores, agentes financeiros, seguradoras, e outros agentes intervenientes, encontra-se, certamente, entre esses fatores críticos. (PIRES et al, 2010)

O desenvolvimento da indústria naval brasileira depende do aproveitamento das oportunidades na indústria de petróleo. Produção com preços competitivos, qualidade e prazo de entrega, dependem de políticas governamentais de financiamento e, para tanto, do apoio constante do governo.

Já para Lima e Velasco (1998), o problema dos estaleiros brasileiros é a ausência de condições organizacionais para competir no mercado internacional, disputando os espaços existentes junto aos armadores europeus e norte-americanos com produtos diferenciados e de alta qualidade, desafio possível de ser assumido pela indústria nacional. Os autores salientam que para disputar esse mercado, há necessidade de uma profunda reestruturação das empresas do setor, compreendendo os seguintes aspectos:

- nova composição societária, preferencialmente que viabilize a conglomeração da indústria naval em moldes similares aos dos estaleiros asiáticos, ou aos que têm sido dominantes no processo de privatização brasileiro (investidores financeiros associados a operadores privados);

- modernização das práticas gerenciais e dos métodos produtivos;

- revisão das estratégias comerciais dos estaleiros, conferindo prioridade ao atendimento do mercado de exportação. 
Assim, a indústria naval brasileira, depois do crescimento nos anos 70, do auge nos anos 80 e da decadência completa até 2000, passa agora por um momento de recuperação, e que esta tem evoluído ao longo dos últimos anos. A retornada deu-se com a construção de plataformas offshore e barcos de apoio e com o auxílio de políticas específicas para o desenvolvimento do setor. A política de compras da PETROBRAS e da TRANSPETRO e o uso do FMM (Fundo da Marinha Mercante) têm estimulado a cadeia de construção naval no Brasil.

\subsection{Indicadores de Desempenho na Indústria Naval}

A indústria de construção naval vive seu melhor momento desde a segunda metade da década de 1970. Depois de praticamente ter desaparecido nos anos 80, o setor começou a dar sinais reais de recuperação em 2004. O crescimento é perceptível a todos mas um meio de medir o desempenho dos estaleiros é ainda fator de discussão devido sua complexidade. A dificuldade de se avaliar o desempenho de um estaleiro é devido a complexidade das operações e aos inúmeros fatores incontroláveis que, na maioria dos casos, não permitem estabelecer valores de referência aplicáveis a qualquer sistema. Alguns autores comentam que o modo ímpar com que as variações dos elementos naturais e operacionais impactam os processos produtivos nos estaleiros tornam difíceis a adoção de indicadores padrões de desempenho. Apesar da dificuldade latente, existe métodos que são usados para o estudo do desempenho na indústria naval conforme apresentado a seguir.

Neste tópico será apresentado o trabalho de Benchmarking Internacional para Indicadores de Desempenho na Construção Naval elaborado por pesquisadores, técnicos e estudantes de graduação e pós-graduação da UFRJ, sob a coordenação do Prof. Floriano C. M. Pires Jr. (Coordenador Geral), Prof. Luiz Felipe Assis e Eng. Cassiano Marins de Souza; e pelo Prof. Thomas Lamb, da Universidade de Michigan, que é um especialista com alto nível de reconhecimento internacional. O trabalho teve os seguintes objetivos:

- Levantamento e análise de indicadores de preço, prazo e qualidade, para construção de navios petroleiros, graneleiros e porta-contêineres, na indústria naval mundial.

- Recomendação de padrões a serem estabelecidos como metas para a construção no Brasil, para as classes relevantes de navios, e padrões de estaleiro.

Os condicionantes e indicadores de desempenho elaborados pelos pesquisadores:
a) Capacidade Física;
b) Tecnologia;
c) Ambiente Industrial;
d) Produtividade;
e) Tempo de Produção; 
f) Qualidade.

\section{Apresentação e análise dos dados}

Com o intuito de verificar práticas gerenciais adotadas por estaleiros estrangeiros e que podem ser adotadas por estaleiros brasileiros, realizou-se entrevistas semiestruturadas com gestores e diretores de um estaleiro brasileiro.

A seguir apresenta-se uma breve descrição das características deste estaleiro, de acordo com indicadores de desempenho voltados para análise de estaleiros:

a) Capacidade Física

O estaleiro em análise possui uma área total de cerca de 550 mil metros quadrados, um dique seco de aproximadamente 130 metros de largura, 350 metros de comprimento e 14 metros de profundidade, além de cais. Possui, ainda:

- linha de painéis e blocos com capacidade nominal de processar em torno de até 11.500 ton/mês de aço;

- pórtico com capacidade de 2.000 t e 210 metros;

- moderna oficina de tubulação com capacidade de aproximadamente 100t/mês;

- cabines de hidrojateamento e pintura "solvente free";

- oficina de blocos curvos;

- extensas áreas de pré-edificação;

- área de lançamento do tipo carreira plana.

Atualmente o Estaleiro é responsável pela produção de dois produtos diferentes. Essa montagem ocorre tanto no Estaleiro como em terceirizados. A montagem que ocorre no Estaleiro é feita tanto na Fábrica de Painéis e Blocos (FPB), preferencialmente, como em áreas abertas. A montagem ocorre em terceirizados porque a demanda é maior que a capacidade atual. Em breve, a FPB estará $100 \%$ operacional e não será necessária a terceirização. A Tabela 1 apresenta as práticas de subcontratação e terceirização adotadas pelo Estaleiro.

Tabela 1 - Práticas de Subcontratação e Terceirização no Estaleiro

\begin{tabular}{cc}
\hline Práticas de Subcontratação e Terceirização & Situação atual \\
\hline Projeto Básico & $\mathrm{X}$ \\
Projeto Detalhado & -- \\
Subcontratação de Trabalhadores na Produção - \% do Total & $25 \%$ \\
Jateamento e Pintura & $\mathrm{X}$ \\
Corte de Chapas & --- \\
Conformação de Chapas de Aço & --- \\
Blocos de Estrutura & $\mathrm{X}$ \\
Blocos Acabados & --- \\
Blocos de Superestrutura & --- \\
Superestruturas Acabadas & $\mathrm{X}$ \\
Cascos Completos & --- \\
Fabricação de Tubulações & $\mathrm{X}$ \\
Acomodações & $\mathrm{X}$ \\
\hline
\end{tabular}

Fonte: Pesquisa de campo (2014) 
Os processos realizados sobre o material estrutural no estaleiro, basicamente o aço (chapas e perfis), são os seguintes:

- Desempeno e estreitamento;

- Transporte (chapas e perfis);

- Shotblasting (lavagem, secagem, jateamento e pintura);

- Corte por CNC (computer numerical control);

- Marcação manual das peças;

- Conformação (para blocos curvos);

- Soldagem em máquinas automáticas

- Transporte (painéis e blocos, por meio de guindastes, kamag e pórticos).

Os processos e equipamentos do Estaleiro para fabricação e montagem de blocos são:

- Guindastes de 70, 100, 200t para logística de chapas, perfis e painéis;

- Shotblasting para lavagem, secagem, jateamento e pintura;

- Máquinas CNC de corte de chapas;

- Máquinas CNC de corte de perfis;

- Máquinas de solda automáticas entre chapas para fabricar painéis;

- Máquinas de solda automáticas entre perfis e chapas para fabricar painéis;

- Esteiras de transporte de chapas, perfis e painéis;

- Pontes rolantes de 15t, 30t e 100t para auxiliar a fabricação e montagem de blocos.

A Tabela 2 apresenta um resumo da capacidade física do estaleiro analisado.

Tabela 2 - Capacidade física do estaleiro

CAPACIDADE FÍSICA

\begin{tabular}{cc}
\hline Área Total $\left(\mathrm{m}^{2}\right)$ & $550.000 \mathrm{~m}^{2}$ \\
Área de Edificação $\left(\mathrm{m}^{2}\right)$ & $45.500 \mathrm{~m}^{2}$ \\
Peso Máximo de Bloco $(\mathrm{t})$ & $2.000 \mathrm{t}$ \\
\hline
\end{tabular}

Fonte: Pesquisa de campo (2014)

b) Tecnologia

Baseado no modelo desenvolvido pelo Prof. Floriano e sua equipe (PIRES et al, 2007) analisou-se o estaleiro em estudo. O modelo aborda os seguintes tópicos: fabricação e montagem, edificação e outfitting, engenharia de produto e de processos e organização e gestão.

Apresenta-se neste trabalho apenas a descrição do nível em que o estaleiro em análise se encontra, que pode ser evidenciado no Quadro 1. 
Quadro 1 - Índice de Desenvolvimento Tecnológico do estaleiro em análise

\begin{tabular}{|c|c|}
\hline & DESENVOLVIMENTO TECNOLÓGICO \\
\hline - Fabricação e Montagem & \\
\hline Armazenagem e Tratamento de Aço & $\begin{array}{l}\text { não tem sistema estruturado de controle de materiais; sistemas magnéticos } \\
\text { de manuseio de chapas e; linha de tratamento automática. }\end{array}$ \\
\hline Corte e Marcação & $\begin{array}{l}\begin{array}{l}\text { possui oxi-corte e plasma } \\
\text { computadorizado. }\end{array} \\
\end{array}$ \\
\hline Submontagem & $\begin{array}{l}\text { estações de trabalho definidas; solda automática; emprego de pontaletes } \\
\text { ajustáveis e; sistemas de planejamento de estocagem de componentes. } \\
\text { Linhas especializadas para submontagens com alto volume de produção; } \\
\text { sistemas integrados e automáticos para posicionamento e soldagem. }\end{array}$ \\
\hline Painéis Planos & posicionamento robotizado de reforços na linha de painelização \\
\hline Montagem & $\begin{array}{l}\text { linha de montagem de blocos; máquinas de solda automáticas e; linhas } \\
\text { especializadas para montagem de blocos; terminais de computadores } \\
\text { locais, com acesso para a equipe de produção; emprego (limitado) de robôs } \\
\text { em soldagem. }\end{array}$ \\
\hline - Edificação e Outfitting & \\
\hline Edificação & $\begin{array}{l}\text { capacidade para edificação simultânea; dique ou sistemas de transferência; } \\
\text { pórticos de maior capacidade; edificação sem excesso de material, através } \\
\text { de controle dimensional e técnicas de controle estatísticos em todas as } \\
\text { fases de fabricação e montagem e; braços telescópicos e plataformas } \\
\text { elevatórias; minimização do emprego de andaimes. }\end{array}$ \\
\hline Outfitting & $\begin{array}{l}\text { outifiting na montagem de blocos e na edificação; construção de módulos } \\
\text { em áreas específicas; módulos geralmente testados antes da instalação e; } \\
\text { maior integração estrutura-outfitting; nível elevado de acabamento } \\
\text { avançado, predominantemente na montagem de blocos; pré-planejamento } \\
\text { extensivo da construção e instalação de módulos e; todos os módulos } \\
\text { testados e pintados antes da instalação. }\end{array}$ \\
\hline - Engenharia de Produto e de Processo & \\
\hline Projeto do Produto & $\begin{array}{l}\text { funções de engenharia abrangentes e complexas, com equipes próprias de } \\
\text { especialistas; banco de dados de grande porte, com atualização contínua; } \\
\text { grande número de projetos disponíveis; trabalhos originais de } \\
\text { desenvolvimento e; emprego de sistemas de modelagem de produto, com } \\
\text { alto grau de integração projeto-produção. }\end{array}$ \\
\hline Engenharia de Produção & $\begin{array}{l}\text { pequeno departamento de engenharia de produção, voltado para } \\
\text { desenvolvimento de recursos e PCP; emprega ferramentas simples (PERT, } \\
\text { CPM) e software de uso comum (Primavera, MS Project); } \\
\text { desenvolvimento extensivo de padrões próprios e; ferramentas de } \\
\text { planejamento e controle de produção desenvolvidos, total ou parcialmente, } \\
\text { in-house. }\end{array}$ \\
\hline - Organização e Gestão & \\
\hline $\begin{array}{l}\text { Layout, Fluxo de Material e Meio } \\
\text { Ambiente }\end{array}$ & $\begin{array}{l}\text { layout bem definido, com arranjo de oficinas adequado ao fluxo da } \\
\text { produção; presença de restrições espaciais não evitáveis e; fluxo de } \\
\text { material geralmente unidirecional }\end{array}$ \\
\hline Sistemas Operacionais & $\begin{array}{l}\text { softwares básicos para funções administrativas e gerenciamento de } \\
\text { projetos (Primavera, MS Project); sistema de recursos humanos, estoque e } \\
\text { suprimentos integrados com planejamento e controle de produção; controle } \\
\text { de estoques e gestão de suprimentos integrados com sistemas financeiro e } \\
\text { contábil. }\end{array}$ \\
\hline Recursos Humanos & $\begin{array}{l}\text { baixa flexibilidade funcional; programas de treinamento para novos } \\
\text { empregados off-the-job; algum treinamento para empregados durante a } \\
\text { carreira e treinamento gerencial para supervisores e; não há programas de } \\
\text { treinamento para os níveis intermediário e sênior e; baixo orçamento de } \\
\text { treinamento. }\end{array}$ \\
\hline Pesquisa e Desenvolvimento & $\begin{array}{l}\text { departamentos ou institutos de pesquisa com atuação nas áreas estratégicas } \\
\text { e; liderança de redes de } \mathrm{P} \& \mathrm{D} \text {. }\end{array}$ \\
\hline
\end{tabular}

Fonte: Pesquisa de campo (2014)

c) Ambiente Industrial 
Os critérios básicos considerados relevantes no ambiente industrial do estaleiro analisado são apresentados no Quadro 2.

Quadro 2-Características do ambiente industrial do estaleiro em análise

\begin{tabular}{|c|c|}
\hline & AMBIENTE INDUSTRIAL \\
\hline \multicolumn{2}{|l|}{ - Organização da cadeia produtiva } \\
\hline Tamanho da indústria naval & $\begin{array}{l}\text { O estaleiro está instalado em um cluster da indústria naval. Existe } \\
\text { importantes interações com a região onde estão localizados os APLs } \\
\text { (Arranjos Produtivos Locais) que compõem a cadeia de fornecedores do } \\
\text { Polo Naval e Offshore que tendem a consolidar este cluster. }\end{array}$ \\
\hline Nível de nacionalização & $\begin{array}{l}\text { Em conformidade com a Política Nacional de Conteúdo Local, o estaleiro } \\
\text { constrói atendendo aos } 70 \% \text { mínimos de nacionalização. O fato de haver } \\
\text { uma série de cascos viabiliza investimentos por parte de fornecedores para } \\
\text { a nacionalização de seus produtos e, sem dúvida, isto está se mostrando } \\
\text { viável. }\end{array}$ \\
\hline \multicolumn{2}{|l|}{ - Recursos humanos } \\
\hline Qualificação dos recursos humanos & $\begin{array}{l}\text { O estaleiro conta hoje com um grande quantitativo de trabalhadores com } \\
\text { formação técnica e cursos superiores das áreas envolvidas, conforme suas } \\
\text { necessidades. }\end{array}$ \\
\hline $\begin{array}{l}\text { Disponibilidade de trabalhadores } \\
\text { qualificados e de engenheiros }\end{array}$ & $\begin{array}{l}\text { No início das atividades do estaleiro era escasso o número de mão-de-obra } \\
\text { (mdo) com capacidade. Foi necessário um tempo destinado a capacitação } \\
\text { da mdo local e o incentivo para trazer mdo de outras localidades. Hoje } \\
\text { aproximadamente } 80 \% \text { é de mdo local. }\end{array}$ \\
\hline $\begin{array}{l}\text { Comprometi-mento do trabalhador com } \\
\text { a companhia }\end{array}$ & $\begin{array}{l}\text { É consenso entre os Gestores do Estaleiro que o comprometimento dos } \\
\text { trabalhadores não é o esperado/desejado. A falta de mdo capacitada } \\
\text { dificulta a dispensa e a seleção dos mais comprometidos. }\end{array}$ \\
\hline Idade média & $\begin{array}{l}\text { A idade média dos trabalhadores é de } 30 \text { anos. Este dado indica a falta de } \\
\text { experiência da mdo em geral. }\end{array}$ \\
\hline $\begin{array}{l}\text { Facilidade de renovação da força de } \\
\text { trabalho }\end{array}$ & $\begin{array}{l}\text { A renovação da força de trabalho é uma atividade problemática no } \\
\text { estaleiro. Ainda não está em sua total utilização da mdo estabelecida nos } \\
\text { histogramas. Muitas novas contratações ainda estão por vir. Esta atividade } \\
\text { fica prejudicada se for necessário, além da contratação de novos } \\
\text { trabalhadores, renovar a equipe já existente. }\end{array}$ \\
\hline \multicolumn{2}{|l|}{ - Políticas de construção naval } \\
\hline $\begin{array}{l}\text { Subsídios diretos e indiretos, incluindo } \\
\text { reserva de mercado, financiamento, } \\
\text { garantias, incentivos fiscais }\end{array}$ & $\begin{array}{l}\text { No caso de incentivos fiscais, no Brasil, alguns regimes especiais } \\
\text { concedem isenção fiscal aos estaleiros. } \\
\text { No Brasil, a garantia é concedida pelo FGCN (Fundo de Garantia para a } \\
\text { Construção Naval). O FGCN tem a finalidade de garantir o risco de crédito } \\
\text { das operações de financiamento à construção naval realizadas pelos } \\
\text { agentes financeiros credenciados a operar com recursos do FMM. Ou seja, } \\
\text { trata-se de um mecanismo criado pelo governo para aumentar os créditos } \\
\text { disponibilizados pelos agentes financeiros do FMM, com redução das } \\
\text { taxas de juros aplicáveis. }\end{array}$ \\
\hline Eficácia do apoio governamental & $\begin{array}{l}\text { O Programa de Modernização e Expansão da Frota (PROMEF) foi uma } \\
\text { medida importante para a criação de demanda aos estaleiros do país, } \\
\text { motivada pelo governo através de sua influência na PETROBRAS. }\end{array}$ \\
\hline Suporte do mercado doméstico & $\begin{array}{l}\text { A PETROBRAS lançou o Programa Empresa Brasileira de Navegação } \\
\text { (EBN } 1 \text { e EBN 2), no segmento de transporte de cargas, visando fomentar } \\
\text { o surgimento de armadores privados nacionais e reduzir a dependência do } \\
\text { mercado externo de fretes para a atividade de cabotagem. }\end{array}$ \\
\hline Sistema de P \& D & $\begin{array}{l}\text { O governo lançou o Plano de Desenvolvimento Produtivo (PDP) para o } \\
\text { desenvolvimento de } 146 \text { novas embarcações de apoio às suas atividades } \\
\text { offshore. }\end{array}$ \\
\hline
\end{tabular}

Fonte: Pesquisa de campo (2014)

\section{d) Produtividade}


O estaleiro em questão mede sua produtividade da forma tradicional com o objetivo de acompanhar a evolução de sua eficiência e de estimar o efetivo necessário para atender a produção planejada de acordo com os prazos contratuais. Por esta razão, a produtividade medida considera diferentes disciplinas em diferentes fases, como:

- Estruturas:

Fabricação: t/hh (toneladas por homem hora)

Montagem: t/hh;

Edificação: metros de solda/hh;

- Tubulação:

Fabricação: t/hh para diferentes tipos de material (aço carbono, cobre níquel, aço inox ou marilloy) e para diferentes diâmetros;

Montagem: $\mathrm{t} / \mathrm{hh}$; idem.

- Elétrica:

Montagem de suportes: $\mathrm{t} / \mathrm{hh}$;

Montagem de bandeja elétrica: metros/hh;

Lançamento de cabos: metros/hh.

De uma forma geral, a produtividade está melhorando provavelmente por 2 razões principais: conhecimento da infraestrutura disponível e das características do produto, e treinamento (experiência).

e) Tempo de Produção

Já o tempo de produção considerado é o tempo desde a fabricação até edificação com todo acabamento e comissionamento, ou seja, o intervalo entre o batimento da quilha e a entrega.

O tempo de entrega do produtos do estaleiro variam. Serão produzidos 8 unidades do produto A, com os seguintes prazos de entrega previstos: aproximadamente 36 meses, 26, 24, 22, 22, 20, 20 e 20 meses. Já o produto B serão produzidos 3 unidades. O tempo de produção dessas unidades será de 48, 42 e 36 meses de construção.

f) Qualidade

O Quadro 3 apresenta os itens referente a Qualidade dos produtos fabricados.

Quadro 3 - Qualidade do estaleiro em atendimento ao mercado

\begin{tabular}{|l|l|}
\hline \multicolumn{2}{|c|}{ QUALIDADE } \\
\hline Qualidade do produto & $\begin{array}{l}\text { Os produtos são certificados pelo ABS e fiscalizados pela PETROBRAS. } \\
\text { Este processo, por si só, indica a qualidade requerida pelo mercado. }\end{array}$ \\
\hline Atendimento de requisitos específicos & $\begin{array}{l}\text { O estaleiro em questão precisa ser flexível para atender ao cliente que } \\
\text { mesmo durante a construção possui demandas que exigem alterações no } \\
\text { projeto. Não raramente, a Engenharia (equipe da Diretoria de Engenharia) } \\
\text { precisa alterar soluções já implementadas, o que exige a mencionada } \\
\text { flexibilidade a existência de uma Engenharia própria. }\end{array}$ \\
\hline Garantia e pós-venda & Responsabilidade do próprio estaleiro. \\
\hline Necessidade de supervisão durante a & No estaleiro em questão existe um grande número de fiscais da \\
\hline
\end{tabular}


O Estaleiro analisado possui uma capacidade física competitiva se compararmos até mesmo com estaleiros estrangeiros. Já o índice de desenvolvimento tecnológico e o ambiente industrial ainda estão em fase de implantação e, portanto, ainda recente para uma análise de benchmark internacional. Quanto a produtividade, o Estaleiro possui um índice mais baixo que os estaleiros estrangeiros, devido ao elevado custo e a grande quantidade de hh ainda usada na produção. Já a qualidade do produto é considerada adequada e competitiva com os estaleiros estrangeiros, uma vez que os produtos recebem certificação da ABS.

\section{Considerações finais}

Devido ao grande tempo de produção da indústria naval, a fabricação de navios não é uma atividade que reage a oscilações de mercado de curto prazo. O comércio internacional só apresenta impacto na atividade em casos de grandes crises, como a do petróleo. Além de custo, qualidade e prazo de entrega, um outro fator decisivo para o sucesso internacional no setor é a oferta de financiamento à produção e à exportação. Por isso a participação do Estado torna-se tão importante.

$\mathrm{Na}$ indústria naval mundial, o Estado tem presença significativa por meio de instrumentos de incentivo e regulação abrangentes: subsídios, reservas de mercado, benefícios fiscais e proteção à cabotagem, políticas marítimas, entre outros. Para o Brasil este é um mercado especialmente relevante tendo em vista as demandas da PETROBRAS e a exploração de petróleo no pré-sal.

A indústria naval brasileira possui vantagens se compararmos a outros países, como: uma mão-de-obra relativamente barata, incentivos do governo e investimentos de grandes empresas que acreditaram no crescimento deste setor.

$\mathrm{O}$ reaquecimento do setor naval favoreceu as associações entre organizações nacionais e estrangeiras. Estas associações permitiram a troca de tecnologias e práticas gerenciais, elevando o nível de maturidade em gerenciamento da indústria como um todo.

A contribuição desse trabalho no momento atual de retomada da indústria naval brasileira torna-se relevante, pois pouco ainda se conhece da nova fase da indústria naval brasileira.

Os resultados do presente estudo permitem concluir que a indústria brasileira de construção naval possui ainda limitações quanto ao desenvolvimento tecnológico e ao ambiente industrial mas apresenta potencial para alcançar níveis razoáveis de competitividade internacional, pois possui capacidade física e qualidade do produto competitivos com estaleiros estrangeiros.

O desenvolvimento deste setor oportuniza ao país uma geração de riqueza e desenvolvimento de longo prazo. Por isso, deve garantir essa expansão no setor petroleiro. A criação de políticas que garantam a evolução da cadeia produtiva devem ser encarados como 
prioridade para que o Brasil garanta uma posição de destaque no setor e, ao mesmo tempo, atinja os objetivos de desenvolvimento econômico e social tão almejados.

\begin{abstract}
In the last decade there has been a resumption of investment in the Brazilian shipbuilding which resulted in an expansion and modernization of the productive capacity of domestic shipyards. National shipyards have yet to reach a level of operational excellence consistent with that seen in the market-leading countries. The paper presents topics adopted by successful foreign shipyards that can be implemented by Brazilian shipyards in order to make them globally competitive. For this, we performed a case study on a national shipyard, whose focus was the identification of technologies and processes in use on this site and its classification with respect to global best practices (benchmarks). A benchmarking method developed for ship building was used in this study. The paper may serve as a source of information to make adjustments to improvements in production processes, reduction of cycle times and better utilization of manpower. Thus, it may help to position the current situation of this shipyard and check needs to make it internationally competitive.
\end{abstract}

Key-words: shipbuilding industry; performance indicators; productive capacity.

\title{
Referências
}

CALDEIRA, J. Mauá: empresário do Império. São Paulo: Companhia das Letras, 1995.

CAMPOS, C. Método de análise de conteúdo: ferramenta para a análise de dados qualitativos no campo da saúde. 2004. Disponível em: http://www.scielo.br/pdf/reben/v57n5/a19v57n5.pdf. Acesso em: 18/08/2013.

COLLINS, G.; GRUBB, M. A. Comprehensive Survey of China's Dynamic Shipbuilding Industry Commercial Development and Strategic Implications. Disponível em: https://www.usnwc.edu/Research---Gaming/China-MaritimeStudies-Institute/Publications/documents/CMS1_Collins-Grubb.aspx. Acesso em: 24/09/2014.

DORES, P. et al. A retomada da indústria naval brasileira. 2012. Disponível em: http://www.bndes.gov.br/SiteBNDES/export/sites/default/bndes_pt/Galerias/Arquivos/conhecimento/livro60anos_persp ectivas_setoriais/Setorial60anos_VOL1ConstrucaoNaval.pdf. Acesso em: 20/06/2013.

KUBOTA, L. C. Indústria naval: um cenário dos principais players mundiais. 2013. Disponível em: http://www.ipea.gov.br/agencia/images/stories/PDFs/nota_tecnica/130225_notatecnicadiset07.pdf. Acesso em: $10 / 09 / 2013$.

LIMA, E. T.; VELASCO, L. O. M. Construção naval no Brasil: existem perspectivas? Revista do BNDES, n. 10. Rio de Janeiro, BNDES, 1998.

MICKEVICIENE, R. Global Competition in Shipbuilding: Trends and Challenges for Europe. 2011. Disponível em: http://cdn.intechopen.com/pdfs-wm/16925.pdf. Acesso em: 24/09/2014.

MOURA, D. A. de. Análise dos principais segmentos da indústria marítima brasileira: estudo das dimensões e dos fatores críticos de sucesso inerentes à sua competitividade. Tese de Doutorado, Escola Politécnica da Universidade de São Paulo. Departamento de Engenharia Naval e Oceânica, São Paulo, 2008.

PASIN, J. Indústria Naval do Brasil: panorama, desafios e perspectivas. Revista do BNDES. v. 9, n. 18, p. 121-148, dez. 2002.

PIRES JÚNIOR, F. et al. Benchmarking internacional para indicadores de desempenho na construção naval. Rio de Janeiro: COPPETEC Fundação, 2007.

PIRES JUNIOR, F. et al. Um sistema integrado para acompanhamento e controle de projetos de construção naval. 2010. Disponível em: http://www.ipen.org.br/Artigos-congresso23-Sobena/SOBENA2010-231.pdf. Acesso em: 20/06/2013. 
PRODANOV, C. C.. Metodologia do trabalho científico: métodos e técnicas da pesquisa e do trabalho acadêmico. 2. ed. Novo Hamburgo: Feevale, 2013.

SANTOS, G.. Análise da evolução da indústria naval. 2011. Disponível em: http://www.uezo.rj.gov.br/tccs/capi/GabrielSantos.pdf. Acesso em: 10/09/2013.

SOUZA, C. M. de. Técnicas avançadas em planejamento e controle da construção naval. Tese (Doutorado em Engenharia Naval). Universidade Federal do Rio de Janeiro, jun, 2009.

\section{Dados dos autores}

Nome completo: Flávia Czarneski

Filiação institucional: Universidade Federal de Rio Grande - FURG

Endereço completo para correspondência: Av. Santos Dumont, 575, Casa 26, Rio Grande, RS, CEP: 96202-450

Telefone para contato: (53) 99001503

e-mail: flavia.furg@gmail.com

Nome completo: Floriano Carlos Martins Pires Júnior ${ }^{2}$

Filiação institucional: Universidade Federal do Rio de Janeiro - UFRJ

Endereço completo para correspondência: Programa de Engenharia Oceânica COPPE/UFRJ.

Caixa Postal 68508, CEP: 21945-970, Rio de Janeiro, RJ

Telefone para contato: (21) 3938-8730, 3938-8731, 3938-8732

e-mail: floriano@peno.coppe.ufrj.br

Submetido em: 2015-01-07

Aceito em: 2015-01-07 